\title{
Interleaved Boost-Half-Bridge Dual-Input DC-DC Converter with a PWM plus Phase- Shift Control for Fuel Cell Applications
}

\author{
Zhang, Zhe; Andersen, Michael A. E.
}

Published in:

Proceedings of IECON 2013

Publication date:

2013

Link back to DTU Orbit

Citation $(A P A)$ :

Zhang, Z., \& Andersen, M. A. E. (2013). Interleaved Boost-Half-Bridge Dual-Input DC-DC Converter with a PWM plus Phase-Shift Control for Fuel Cell Applications. In Proceedings of IECON 2013 IEEE.

\section{General rights}

Copyright and moral rights for the publications made accessible in the public portal are retained by the authors and/or other copyright owners and it is a condition of accessing publications that users recognise and abide by the legal requirements associated with these rights.

- Users may download and print one copy of any publication from the public portal for the purpose of private study or research.

- You may not further distribute the material or use it for any profit-making activity or commercial gain

- You may freely distribute the URL identifying the publication in the public portal

If you believe that this document breaches copyright please contact us providing details, and we will remove access to the work immediately and investigate your claim. 


\title{
Interleaved Boost-Half-Bridge Dual-Input DC-DC Converter with a PWM plus Phase-Shift Control for Fuel Cell Applications
}

\author{
Zhe Zhang and Michael A. E. Andersen \\ Dept. of Electrical Engineering, Technical University of Denmark \\ Kgs. Lyngby, Denmark \\ zz@elektro.dtu.dk and ma@elektro.dtu.dk
}

\begin{abstract}
This paper presents an isolated dual-input DC-DC converter with a PWM plus phase-shift control for fuel cell hybrid energy systems. The power switches are controlled by phase shifted PWM signals with a variable duty cycle, and thus the two input voltages as well as the output voltage can be regulated effectively. By using the second input capacitor and the high side switches as an inherent active clamping circuit, zerovoltage switching (ZVS) for the power MOSFETs on the primary side, and zero-current switching (ZCS) for the diodes on the secondary side are achieved respectively to improve the performance of the proposed PWM converter. The principle of operation is analyzed and some design considerations are discussed. Simulation results using PLECS are given to verify the proposed analysis and design. An experimental converter prototype has been designed, constructed and tested in the laboratory to verify the validity of the theoretical analysis and also demonstrate the converter's performance over wide variations in input voltage.
\end{abstract}

Keywords-Boost-half-bridge, converter, fuel cell, multipleinput, phase-shift control, soft-switching.

\section{INTRODUCTION}

Applying clean and renewable energy sources, such as wind energy, solar energy and hydrogen, has long been a focus for concern in both academia and industry. Proton exchange membrane (PEM) fuel cells are considered as a good candidate for many applications, for example, automotive propulsion, due to their zero emission, low operating temperature and high power density [1]-[3]. Generally speaking, fuel cells can be implemented either as a standalone system or in combination with other power/energy sources such as a battery and/or a super-capacitor bank. Hybridization can distinctly improve the system performance on various aspects, such as decreasing fuel cell cost, isolating the fuel cell from load fluctuations and enhancing the dynamic response. Hence, hybrid fuel cell power conversion systems are well suited for the applications where the average power demand is low whilst load dynamics is relatively high [4]-[6]. For this reason, how to merge the different renewable energy source elements together as a hybrid power conversion system and control the power flows effectively has become a really interesting topic [3] during the last decade. Furthermore, in the grid-tie applications fuel cells are often faced with the need of boosting their low output voltage to the much higher DC-link voltage which is required

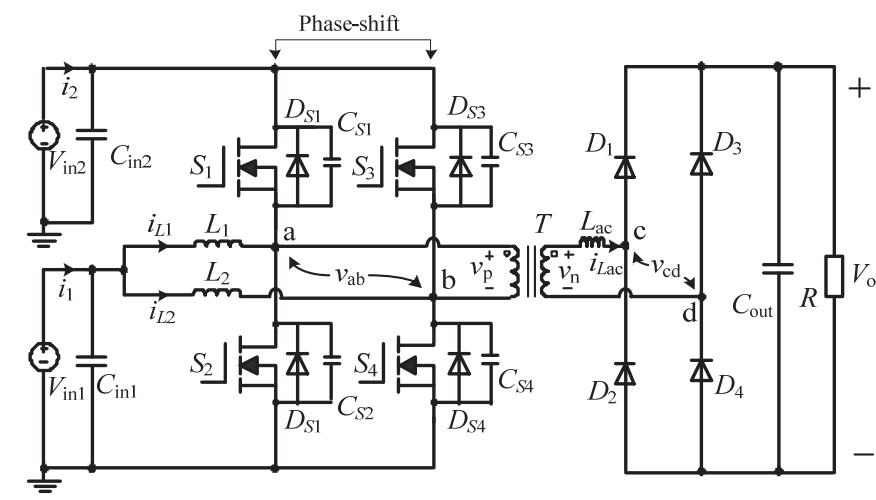

Fig. 1: Topology of the interleaved boost-half-bridge DC-DC converter.

for a single/three-phase utility grid [7]. Hence, in order to fulfill different system requirements, various hybrid system structures and converter topologies have been proposed and investigated. For the applications where galvanic isolation is required, as reviewed in [3], basically, there are two categories classified as: multiple-converter system and multiple-port system. Of the two solutions, a multiple-port system can have higher power density and lower cost, due to the fact that some component parts of the converter, such as transformers, rectifiers and filters can be shared by the different input power ports. Accordingly multiple-port converters have been receiving more and more attention in recent years. A general solution to generate an isolated multiple-port converter is to adopt the magnetic coupling solution. Half-bridge, full-bridge, and their combination can be employed regarding the system constraints imposed by features of various input power sources [8]-[12].

In [13], a ZVS half-bridge inductive DC-DC converter with the active clamped circuit under pulse-width modulation (PWM) control strategy was investigated. Based on this topology, if another input is connected with the DC-link on the primary side instead of the clamp capacitor in the ZVS circuit, therefore, a new dual-input converter can be derived from it, as shown in Fig. 1. The proposed converter consists of two interleave boost-half-bridge (BHB) circuits [14], [15], a transformer and a full-bridge diode rectifier. An AC inductor, which is the sum of the leakage inductance and the auxiliary inductance, is the power interface element between two sides of the transformer. In order to decouple the two power inputs 
as well as effectively regulate the output voltage, the duty cycle plus a phase-shift control [16]-[18] is adopted in this paper. The duty cycle of the converter is used to adjust the voltage of the two independent inputs, $V_{\text {in1 }}$ and $V_{\text {in2, }}$, while the phase-shift angle is employed to regulate the output voltage accordingly.

This paper is organized into five sections: following the introduction, the topology and operation principle of the proposed converter are presented in Section II. Analysis on circuit performance is given in Section III. Simulation and experimental results are provided in Section IV. Finally, a conclusion is drawn in Section V.

\section{Operating PRINCIPLE OF THE PROPOSED DUAL-INPUT DC-DC CONVERTER}

As shown in Fig.1, the dual-input DC converter has two inputs, two input inductors, $L_{1}$ and $L_{2}$, an AC inductor $L_{\mathrm{ac}}$, four power MOSFETs $S_{1} \sim S_{4}$, and high frequency (HF) transformer. $V_{\text {in } 1}$ and $V_{\text {in2 }}$ are denoted as voltage of the two power inputs; $i_{\mathrm{L} 1}$ and $i_{\mathrm{L} 2}$ are defined as the inductor currents; $v_{\mathrm{ab}}$ is the voltage between the midpoints of two bidirectional boost/buck half bridges; and $i_{\mathrm{Lac}}$ is the secondary side current.

\section{A. PWM modulation only (duty cycle control)}

In this case, the phase shift angle, $\varphi$, is kept at $\pi$ as a constant to reduce the current ripple, while the duty cycle is the only control variable. $S_{1}$ and $S_{2}$, as well as $S_{3}$ and $S_{4}$, have complementary gate signals with a deadband. So the relationship of $V_{\text {in1 }}$ and $V_{\text {in2 }}$ can be expressed

$$
V_{i n 1}=V_{i n 2} \cdot(1-D)
$$

Where $D$ is the duty cycle of the high side switches $S_{2}$ and $S_{4}$.

Under different operating conditions, $i_{L a c}$ can have different waveforms (discontinues or continues), as illustrated in Fig. 2 (a) and (b). From the waveforms represented in Fig. 2 (a), the rise or fall slopes of $i_{L \mathrm{ac}}$ can be calculated by

$$
L_{\mathrm{ac}} \cdot \frac{\mathrm{d} i_{\mathrm{Lac}}}{\mathrm{d} t}= \begin{cases}\frac{n V_{i n 1}}{1-D}-V_{o} & t_{0} \leq t<t_{1} \\ -V_{o} & t_{1} \leq t \leq t_{2}\end{cases}
$$

When the converter operating with the waveforms shown in Fig. 2(b), there will be one more state where $v_{\mathrm{ab}}$ and $v_{\mathrm{cd}}$ have opposite direction (during $t_{0} \sim t_{1}$ ) and therefore it can be expressed

$$
L_{\mathrm{ac}} \cdot \frac{\mathrm{d} i_{\mathrm{Lac}}}{\mathrm{d} t}=\frac{n V_{\text {in } 1}}{1-D}+V_{o}
$$

\section{B. Phase-shift control only}

For dual-active bridge type of converters, the phase-shift control is the most widely used control method. The halfbridges $a$ and $b$ in the converter can be defined as leading and lagging legs, respectively. Accordingly, the duty cycle of the power MOSFETs is kept at 0.5. Since essentially the dutycycle control and the phase-shift control are same from the output voltage regulation perspective, the proposed converter will have the same operating waveforms as shown in Fig. 2.

\section{Duty-cycle plus duty-cycle control}

In order to decouple the two inputs effectively and also regulate the output accurately, both the duty cycle and the phase-shift angle can be adopted as the control variables at the same time, and thereby the converter will have more complex behaviors.

Due to the operation symmetry, the variation range of the phase-shift angle $\varphi$ is: $0<\varphi<\pi$. Depending on the duty cycle and its relationship with the phase-shift angle, actually there are three operational cases existing and can be classified into: complete demagnetized, partial demagnetized and magnetized conditions and the typical waveforms are shown in Fig. 3 where $\varphi / 2 \pi<\min [D$, $(1-D)]$.

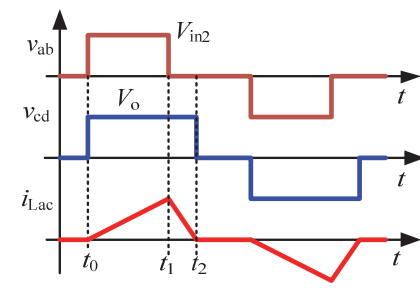

(a)

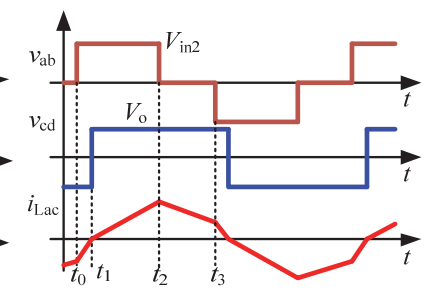

(b)
Fig. 2: Typical waveforms. (a) Discontinues $i_{L \mathrm{ac}}$, and (b) continues $i_{L \mathrm{ac}}$.

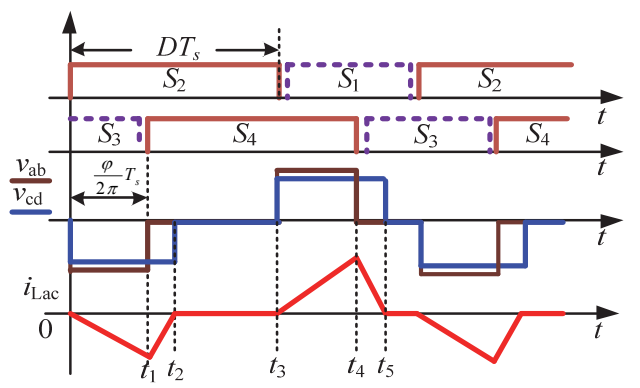

(a)

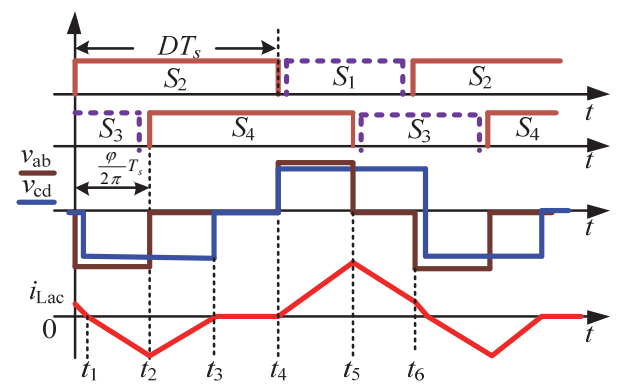

(b)

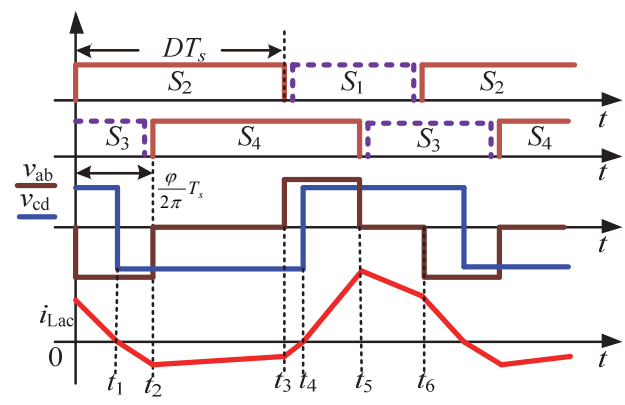

(c)

Fig. 3: Typical operating waveforms with duty-cycle plus phase-shift control: (a) case 1 , (b) case 2 , and (c) case 3 . 
Case 1: as shown in Fig. 3 (a), the AC current is totally demagnetized, so during time interval $T_{s} \cdot \varphi / 2 \pi$ the increment of the inductor current should satisfy the following:

$$
\begin{gathered}
I_{L a c}\left(t_{4}\right)=-I_{L a c}\left(t_{1}\right)=\frac{n V_{a b}-V_{c d}}{L_{a c}} \cdot \frac{\varphi}{2 \pi} \cdot T_{s} \\
\Delta t=t_{5}-t_{4}=\frac{I_{L a c}\left(t_{4}\right)}{V_{c d}} \cdot L_{a c}
\end{gathered}
$$

Hence, output power of the converter as a function of the phase-shift angle can be derived as:

$$
P_{o}=V_{o} \cdot \frac{2}{T_{s}} \int_{t_{3}}^{t_{5}} i_{L a c}(t) d t=\frac{m(m-1)}{L_{a c} \cdot f_{s}} \cdot\left(\frac{\varphi}{2 \pi}\right)^{2} \cdot\left(V_{o}\right)^{2}
$$

where

$$
m=\frac{n V_{a b}}{V_{c d}}=\frac{n V_{i n 1}}{(1-D) V_{o}}=\frac{n V_{i n 2}}{V_{o}}
$$

Case 2: as shown in Fig. 3 (b), the AC current is partially demagnetized, so its peak values can be expressed

$$
\begin{gathered}
i_{L a c}\left(t_{5}\right)=\frac{n V_{a b}-V_{c d}}{L_{a c}} \cdot \frac{\varphi}{2 \pi} \cdot T_{s} \\
i_{L a c}\left(t_{6}\right)=i_{L a c}\left(t_{0}\right)=i_{L a c}\left(t_{5}\right)-\frac{V_{c d}}{L_{a c}} \cdot\left[(1-D)-\frac{\varphi}{2 \pi}\right] \cdot T_{s} \\
i_{L a c}\left(t_{2}\right)=\frac{V_{c d}-n V_{a b}}{L_{a c}} \cdot\left(\frac{\varphi}{2 \pi} \cdot T_{s}-\Delta t_{1}\right)=-\frac{V_{c d}}{L_{a c}} \cdot\left(t_{3}-t_{2}\right)
\end{gathered}
$$

where

$$
\Delta t_{1}=t_{1}-t_{0}=\frac{i_{L a c}\left(t_{6}\right) \cdot L_{a c}}{n V_{a b}-V_{c d}}
$$

Therefore, output power of the converter as a function of phase-shift angle and duty-cycle is calculated by

$$
P_{o}=V_{o} \cdot \frac{1}{T_{s}} \cdot\left[\int_{t_{4}}^{t_{6}} i_{L a c}(t) d t+\int_{t_{0}}^{t_{3}}\left|i_{L a c}(t)\right| d t\right]
$$

Case 3: in this case, the AC current has no zero periods as shown in Fig. 3 (c). According to the waveforms, the peak values of the $\mathrm{AC}$ current and the corresponding time intervals can be calculated from the piece-wised formulas as follows,

$$
\begin{gathered}
i_{L a c}\left(t_{5}\right)-i_{L a c}\left(t_{6}\right)=\frac{V_{c d}}{L_{a c}} \cdot\left[(1-D)-\frac{\varphi}{2 \pi}\right] \cdot T_{s} \\
i_{L a c}\left(t_{5}\right)=\frac{n V_{a b}-V_{c d}}{L_{a c}} \cdot\left[\frac{\varphi}{2 \pi} \cdot T_{s}-\left(t_{4}-t_{3}\right)\right] \\
i_{L a c}\left(t_{6}\right)=i_{L a c}\left(t_{0}\right)=\frac{n V_{a b}+V_{c d}}{L_{a c}} \cdot\left(t_{1}-t_{0}\right) \\
i_{L a c}\left(t_{2}\right)-i_{L a c}\left(t_{3}\right)=-\frac{V_{c d}}{L_{a c}} \cdot\left[D-\frac{\varphi}{2 \pi}\right] \cdot T_{s} \\
-i_{L a c}\left(t_{2}\right)=\frac{n V_{a b}-V_{c d}}{L_{a c}} \cdot\left[(1-D) T_{s}-\left(t_{1}-t_{0}\right)\right] \\
-i_{L a c}\left(t_{3}\right)=\frac{n V_{a b}+V_{c d}}{L_{a c}} \cdot\left(t_{4}-t_{3}\right)
\end{gathered}
$$

Hence, similarly, the average output power in this case can be calculated by

$$
P_{o}=V_{o} \cdot\left|i_{L a c}\right|_{\text {avg }}=V_{o} \cdot \frac{1}{T_{s}} \cdot \int_{t_{0}}^{t_{6}}\left|i_{L a c}(t)\right| d t
$$

Although the aforementioned three operating cases have different characteristics, Case 1 is the most typical one in practice and thereby in this paper only this case is represented and analyzed in detail in order to avoid prolixity.

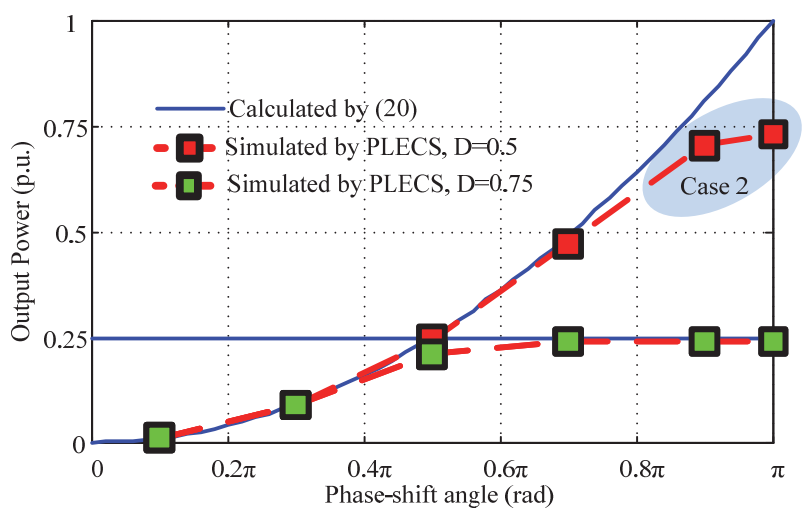

Fig. 4: Comparison of the calculated results and the simulated results $(m=1.2)$.

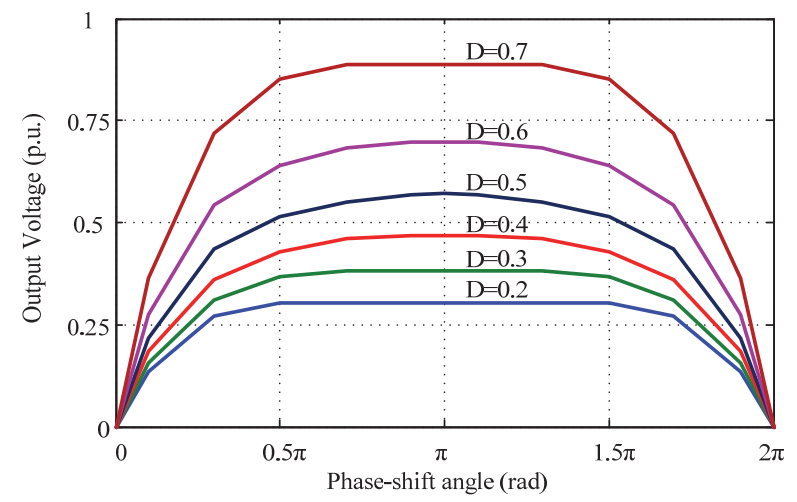

Fig. 5: Output voltage as a function of phase-shift angle with different $m$ and $D$.

In Case 1, if the converter operating condition is different from that shown in Fig. 3 (a), i.e. $\varphi / 2 \pi>D$ or $(1-D)$, based on the corresponding waveforms, the converter output power can be derived as well. Eventually, in Case 1, output power can be summarized as

$$
P_{o}=\left\{\begin{array}{cc}
\frac{m(m-1)\left(V_{o}\right)^{2}}{L_{a c} \cdot f_{s}} \cdot\left(\frac{\varphi}{2 \pi}\right)^{2}, & \varphi / 2 \pi<\min [D,(1-D)] \\
\frac{m(m-1)\left(V_{o}\right)^{2}}{L_{a c} \cdot f_{s}} \cdot D^{2}, & D<\varphi / 2 \pi<0.5 \\
\frac{m \cdot(m-1)\left(V_{o}\right)^{2}}{L_{a c} \cdot f_{s}} \cdot(1-D)^{2}, & 1-D<\varphi / 2 \pi<0.5
\end{array}\right.
$$

From (20), it is noted that the phase-shift angle cannot regulate the output power when $\varphi / 2 \pi>1-D(D>0.5)$ and when $\varphi / 2 \pi>D(D<0.5)$. In order to verify the validity of the theoretical calculation process, the converter is simulated by the circuitry simulation software, PLECS. Hereby, the results of calculation and simulation can be plotted in a same frame and compared in Fig. 4. It can be seen that since $\varphi / 2 \pi>0.25$, the output power is not a function of the phase-shift angle and will follow an upper limit which is relative to the duty cycle as described in (20), On the other hand, when the converter is supplied with a constant input voltage and connected by a constant resistive load, changing the phase-shift angle will lead to a variable $m$, so that in this condition the output voltage as a function of phase-shift angle is presented in Fig. 5 . 


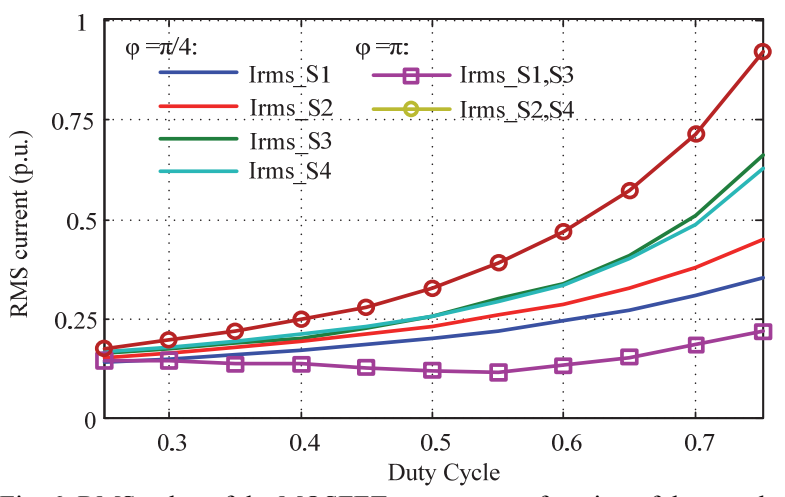

Fig. 6: RMS value of the MOSFET currents as a function of duty cycle.

\section{DESIGN CONSIDERATIONS}

\section{A. Soft-switching performance}

Basically, ZVS can be deduced on the precondition that the anti-parallel diode of the MOSFET must conduct before the MOSFET is triggered. In other words, the main devices are turned off with a positive current flowing and then the current diverts to the opposite diode which allows the in-coming MOSFET to be switched on under zero voltage. In this paper, unlike the conventional phase-shift full-bridge converter, due to the input inductor currents $i_{\mathrm{L} 1}$ and $i_{\mathrm{L} 2}$, the proposed converter has relatively more complicated ZVS performance to analyze.

The currents flowing through the MOSFETs $S_{1} \sim S_{4}$ must be negative when the corresponding MOSFET is triggered, so the following relationships must be satisfied to receive ZVS operations,

$$
\left\{\begin{array}{c}
I_{L 1, \max }-I_{L a c}>0, \text { for } S_{1} \\
I_{L 1, \min }-I_{L a c}<0, \text { for } S_{2} \\
I_{L 2, \text { max }}-\left|I_{L a c}\right|>0, \text { for } S_{3} \\
I_{L 2, \text { min }}-\left|I_{L a c}\right|<0, \text { for } S_{4}
\end{array}\right.
$$

where

$$
\begin{aligned}
& I_{L i, \max }=\frac{P_{i n}}{2 V_{i n 1}}+\frac{(1-D) V_{i n 1}}{2 L_{i}} \quad(i=1,2) \\
& I_{L i, \min }=\frac{P_{i n}}{2 V_{i n 1}}-\frac{(1-D) V_{i n 1}}{2 L_{i}} \quad(i=1,2) .
\end{aligned}
$$

\section{B. Current distribution in primary side MOSFETS}

Like all half-bridge boost derived converters, the current distribution in the primary side MOSFETs is unequal, and here the analysis on the RMS current distribution is even more complex due to the variable phase-shift angle.

If $\varphi=\pi$, the RMS current of the MOSFETs can be calculated by

$$
\begin{gathered}
I_{R M S, S 1}=I_{R M S, S 3}<I_{R M S, S 2}=I_{R M S, S 4} \\
I_{R M S, S 2}=I_{R M S, S 4}=\sqrt{I_{L a c, R M S^{2}+I_{L 1, R M S}{ }^{2}}} \\
I_{R M S, S 1}=I_{R M S, S 3}=\sqrt{I_{L a c, R M S^{2}-I_{L 1, R M S}}}
\end{gathered}
$$

If $\varphi \neq \pi$, then the expressions to calculate the RMS current of each switch depend on $\varphi$ and of course are more complex, so it will not be derived here.

Fig. 6 plots the RMS current as a function of duty cycle $D$ instead of output power or phase shift $\varphi$. It can be found that, if $\varphi=\pi$, the low side switches $S_{2}$ and $S_{4}$ will have the maximum RMS current, whereas the high side switches $S_{1}$ and $S_{3}$ will have the minimum RMS current. This phenomenon may be considered when choose components and make thermal design.

\section{EXPERIMENTAL RESULTS}

The proposed interleaved boost-half-bridge dual-input DC-DC converter in Fig. 1 has been simulated, designed, built and tested to validate the previous introduced analysis and converter's overall performance. The specifications and the employed components of the constructed converter are listed in Table I. Fig. 7 also shows the laboratory setup for the

\begin{tabular}{|c|c|}
\hline Parameters & Values \\
\hline $\begin{array}{l}\text { Input voltage } \\
\text { Maximum output power } \\
S_{1} \sim S_{4} \\
D_{1} \sim D_{4} \\
\text { Transformers } T \\
\text { Inductors } L_{1} \text { and } L_{2} \\
\text { Inductor } L_{\text {ac }} \\
\text { Switching frequency } \\
\text { Digital controller }\end{array}$ & $\begin{array}{l}V_{\text {in1 }}: 30-60 \mathrm{VDC} ; V_{\text {in2_max }}: 120 \mathrm{VDC} \\
1.5 \mathrm{~kW} \\
\text { IRFB4115 }(150 \mathrm{~V} / 104 \mathrm{~A}) \\
\text { HFA08TB60 }(600 \mathrm{~V} / 8 \mathrm{~A}) \\
4: 16, \text { Ferrite N87 } \\
55 \mu \mathrm{H} \text { N41 gapped RM core; } \\
20 \mu \mathrm{H} \\
60 \mathrm{kHz} \\
\text { TMS320F28027 DSP }\end{array}$ \\
\hline
\end{tabular}
proposed converter. The prototype is implemented by a digital PWM controller (TMS320F28027) and the gate driver IR2110S to generate four gate signals with adjustable duty cycle and phase-shift angle.

TABLE I: PARAMETERS AND COMPONENTS USED IN HARDWARE

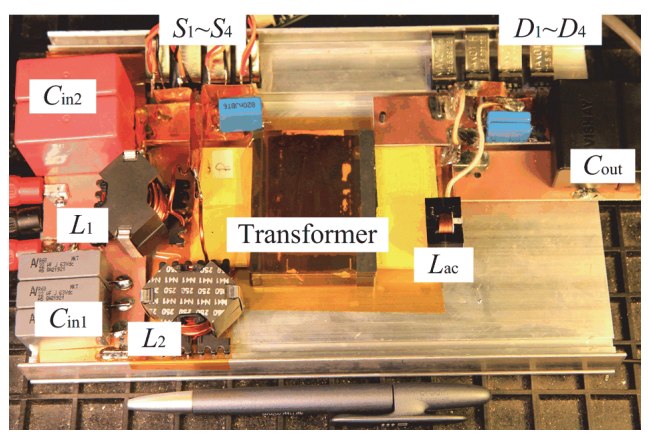

Fig. 7: Photograph of a $1.5 \mathrm{~kW}$ laboratory prototype.

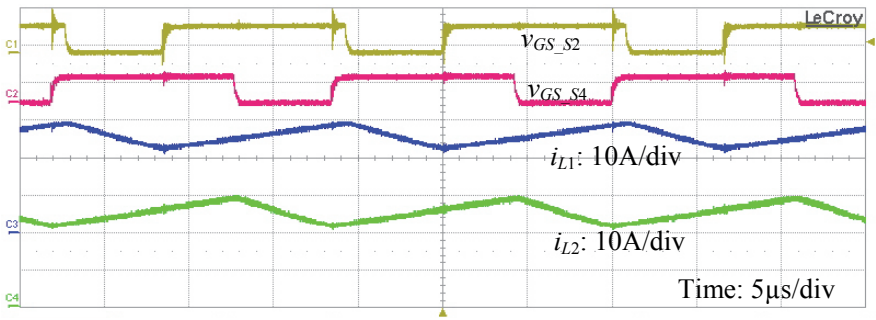

Fig. 8: Experimental results of the phase-shifted gate voltage of $S_{2}$ and $S_{4}$ and the inductor currents $i_{L 1}$ and $i_{L 2}$. 


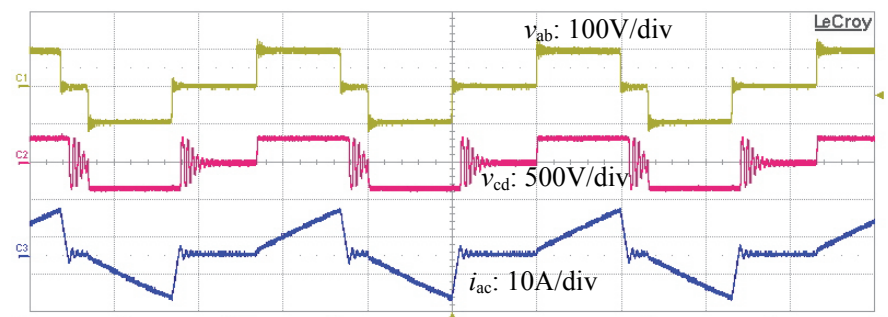

(a)

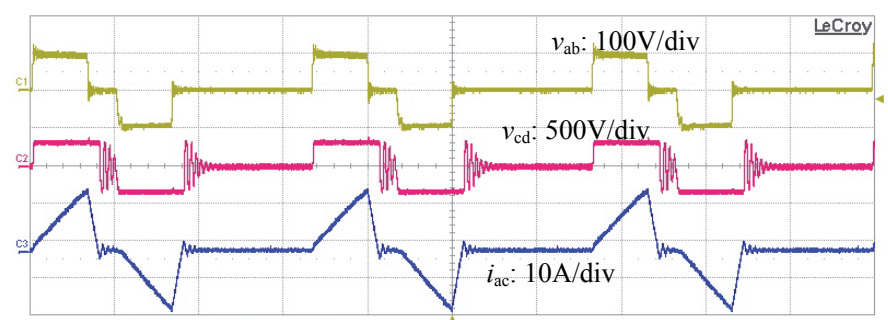

(b)

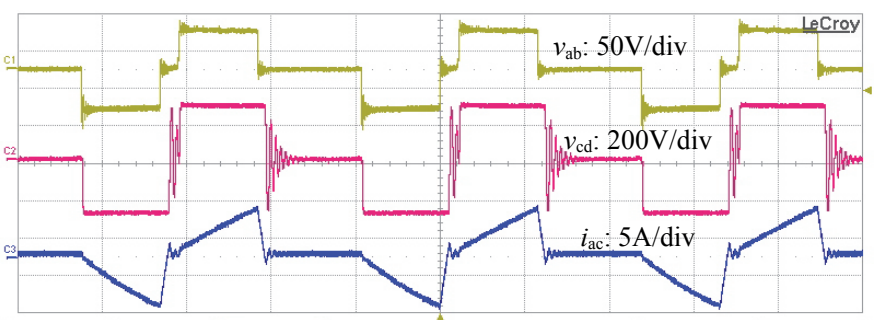

(c)

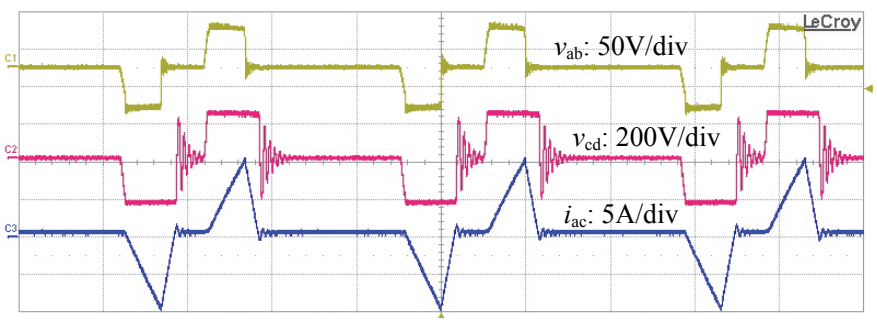

(d)

Fig. 9: Experimental results of the high frequency AC voltages and current of $v_{\text {ab }}, v_{\text {cd }}$ and $i_{\text {Lac }}$ at $V_{\text {in } 1}=30 \mathrm{~V}$ and (a) $\varphi=0.8 \pi$ and $D=0.7$, (b) $\varphi=0.4 \pi$ and $D=0.7$, (c) $\varphi=0.5 \pi$ and $D=0.3$ and (d) $\varphi=0.2 \pi$ and $D=0.3$. (Time: $5 \mu \mathrm{s} / \mathrm{div}$ ).

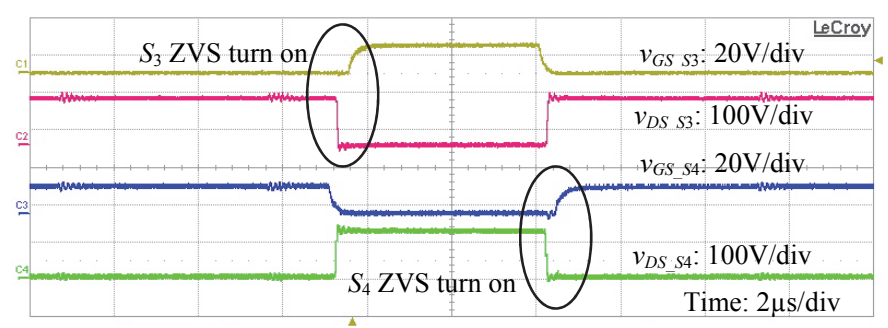

Fig. 10: Experimental results of the gate voltage and drain voltage of $S_{3}$ and $S_{4}$ at light load: $V_{\mathrm{in} 1}=35 \mathrm{~V}$, and $\varphi=0.8 \pi$ and $D=0.7$.

The measured waveforms of the PWM signal $v_{G S_{-} S 2}$ and $v_{G S S 4}$ and two phase-shifted inductor currents $i_{\mathrm{L} 1}$ and $i_{\mathrm{L} 2}$ at $\varphi=\overline{0} .8 \pi$ are illustrated in Fig. 8 .

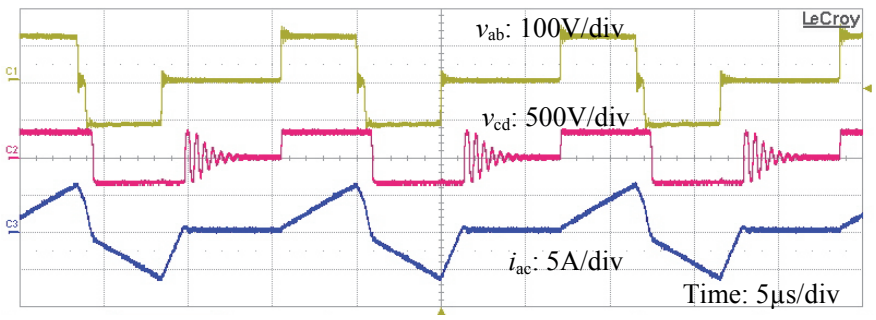

Fig. 11: Experimental waveforms of $v_{\mathrm{ab}}, v_{\mathrm{cd}}$ and $i_{\text {Lac }}$ in Case 2: $\varphi=0.45 \pi$ and $D=0.7$.

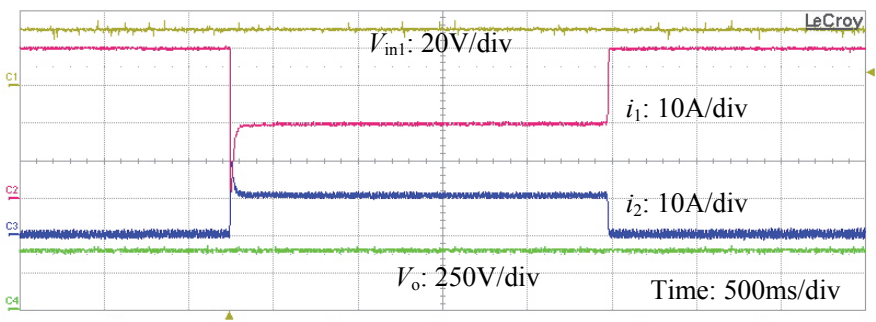

Fig. 12: Experimental results of the dynamic operation of the converter with two power inputs.

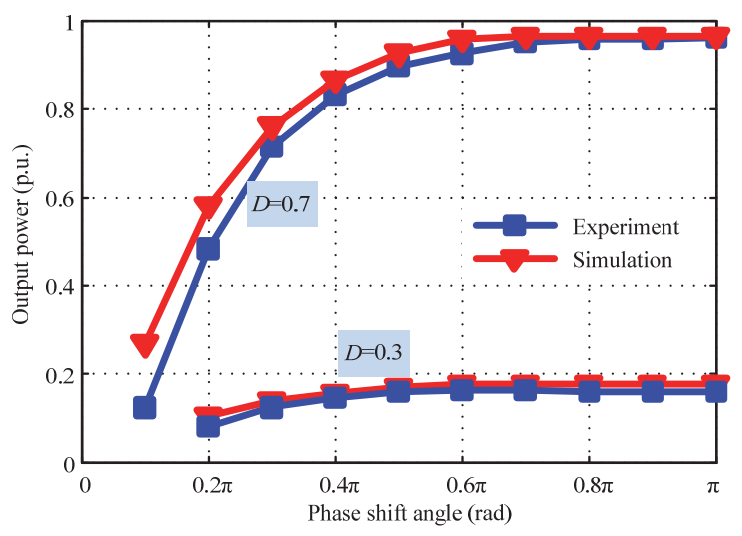

Fig. 13: Comparison of the results of simulation and experiment.

The measured high frequency ac voltages and current of $v_{\mathrm{ab}}, v_{\mathrm{cd}}$ and $i_{\text {Lac }}$ at $V_{\mathrm{in} 1}=30 \mathrm{~V}$ and different phase-shift angles and duty cycles are given in Fig. 9. It can be found that by using the capacitor $C_{\text {in2 }}$ and high side switches $S_{1}$ and $S_{3}$ as an active clamp circuit, the voltage transient spike across the current-fed bridge is limited. The experimental waveforms match the typical waveforms given in Section II very well.

According to the waveforms of ZVS operation shown in Fig. 10, the drain voltage $v_{D S_{-} S 3}$ and $v_{D S_{-} S 4}$ are all decreased to zero before switches $S_{3}$ and $S_{4}$ are turned $\mathrm{ON}$, and there are no transient voltage spikes and rings across the switches. Therefore, the converter will have proximate zero switching losses and lower electromagnetic noises.

As an example, if a larger $\mathrm{AC}$ inductor is used $(66 \mu \mathrm{H})$, the converter will operate in Case 2 and the experimental waveforms are presented in Fig. 11 and it can be seen that there is a different current fall slope existing in this condition as the typical waveform given in Fig. 3(b). 


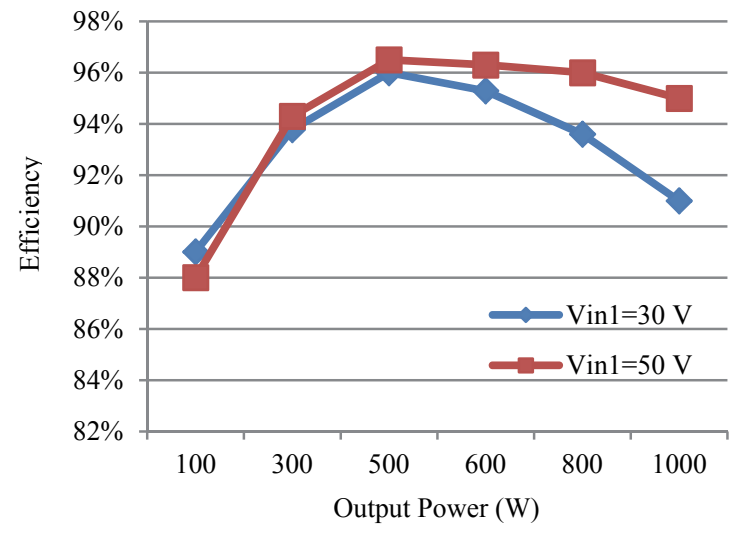

Fig. 14: Measured efficiency curve of the converter.

In order to verify the capability of the dual inputs simultaneous operation, power supply $V_{\text {in2 }}$ is switched $\mathrm{ON}$ and OFF alternately, so that the input current $i_{2}$ jumps between zero and $10 \mathrm{~A}$, as shown in Fig. 12, and the output voltage can be regulated as a constant regardless of $V_{\text {in2 }}$.

Furthermore, a comparison between the simulation results and experimental results is given in Fig. 13, and they match well so the validity of the theoretical analysis can be proved. Finally, Fig. 14 shows the efficiency curve of the DC-DC converter built in the lab. The efficiency above $90 \%$ at worst operating condition (lowest input voltage and highest output power) is obtained and optimal design of the proposed converter in order to heighten the efficiency even further can be a topic for the future work.

\section{CONCLUSION}

In this paper, an isolated dual-input DC-DC converter using phase-shifted PWM control is presented, and it appears very attractive in the application as an interface converter for renewable energy system. The operating principle and design considerations are discussed and verified by simulation and experiment. The proposed converter is capable of achieving decoupled input voltage and regulated output voltage by the PWM plus phase-shift control. All the switches can be turned ON under the ZVS condition and all the diodes can be turned OFF under ZCS condition, and therefore the electromagnetic noises can be attenuated effectively. Nonetheless, the proposed converter also has some drawbacks such as relatively complicated control and unequal current distribution in the high position and low side MOSFETs. The magnetic elements are required to be optimized in order to improve efficiency further and closed loop control will follow in future publications.

\section{REFERENCES}

[1] F. Blaabjerg, Z. Chen and S. B. Kjaer, "Power electronics as efficient interface in dispersed power generation systems," IEEE Trans. Power Electron. 2004, 19, (5), pp.1184-1194.

[2] Z. Chen, J. Guerrero, and F. Blaabjerg, "A review of the state of the art of power electronics for wind turbines," IEEE Trans. Power Electron., 2009, 24, (8), pp. 1859-1875.

[3] Z. Zhang, R. Pittini, M. A. E. Andersen and O. C. Thomsen, "A review and design of power electroncis converters for fuel cell hybrid system applicaions," Energy Procedia, vol.20, pp.301-310, 2012.

[4] W. Zhang, D. Xu, X. Li and etc., "Seamless transfer control strategy for fuel cell unierryptible power supply system," IEEE Trans. Power Electron., vol.28, no.2, pp.717-729, Feb. 2013.

[5] Z. Zhang, O. C. Thomsen and M. A. E. Andersen, "Optimal design of push-pull-forward half-bridge (PPFHB) bidirectional dc-dc converter with variable input voltage," IEEE Trans. Ind. Electron., vol.59, no.7, pp.2761-2771, Jul. 2012.

[6] A. Tani, M. Camara, B. Dakyo and Y. Azzouz, "DC/DC and DC/AC converters control for hybrid electric vhicles energy managementultracapacitors and fuel cells," IEEE Trans. Ind. Inform., vol.9, no.2, pp.689-696, May 2013.

[7] H. Hu, S. Harb, N. Kutkut, I. Batarseh and Z. J. Shen, "A review of power decoupling techniques for microinverter with three different decoupling capacitor locations in PV system," IEEE Trans. Power Electron., vol.28, no.6, pp.2711-2726, Jun. 2013

[8] H. Cha, J. Choi and P. N. Enjeti, "A three-phase current-fed DC/DC converter with active clamp for low-dc renewable energy sources," IEEE Trans. Power Electron., 2008, 23, (6), pp.2784-2793.

[9] H. Tao, A. Kotsopoulos, J.L. Duarte and M.A.M. Hendrix, "Transformer coupled multiport ZVS bidirectional DC-DC converter with wide input range," IEEE Trans. Power Electron., Vol. 23, no.2, pp.771-781, March. 2008.

[10] H. Krishnaswami and N. Mohan, "Three-port series-resonant DC-DC converter to interface renewable energy sources with bidirectional load and energy storage ports," IEEE Trans. Power Electron., vol.24, no.10, pp.2289-2297, Oct. 2009.

[11] Z. Zhang, O. C. Thomsen, M. A. E. Andersen and H. R. Nielsen, "Dualinput isolated full-bridge boost DC-DC converter based on the distributed transformers," IET Power Electron., vol.5, no.7, Aug. 2012.

[12] Z. Zhang, O. C. Thomsen and M. A. E. Andersen, "Analysis and design of a bidirectional isolated dc-dc converter for fuel cells and supercapacitors hybrid system," IEEE Trans. Power Electron., vol.27, no.2, pp.848-859, Feb. 2012.

[13] Y. Lembeye, V. D. Bang, G. Lefever and J.-P Ferrieux, "Novel halfbridge inductive dc-dc isolated converters for fuel cell applications," IEEE Trans. Enery Conv., vol.24, no.1, pp.203-210, Mar. 2009.

[14] Z. Zhang, O. C. Thomsen and M. A. E. Andersen, "Soft-switched dualinput DC-DC converter combining a boost-half-bridge cell and a voltage-fed full-bridge cell," IEEE Trans. Power Electron., vol.28, no.11, pp.4897-4902, Nov. 2013.

[15] C. Park and S. Choi, "Quasi-resonant boost-half-bridge converter with reduced turn-off switching loss for $16 \mathrm{~V}$ fuel cell application," IEEE Trans. Power Electron., vol.28, no.11, pp.4892-4896, Nov. 2013.

[16] D. Xu, C. Zhao and H. Fan, "A PWM plus phase-shift control bidirectional DC-DC converter" IEEE Trans. Power Electron., vol. 19, no. 3, pp.666-675, Mar. 2004.

[17] H. Xiao and S. Xie, "A ZVS bidirectional DC-DC converter with phaseshift plus PWM control scheme," IEEE Trans. Power Electron., vol.23, no.4, pp.813-823, Feb. 2008.

[18] W. Li, J. Xiao, Y. Zhao and X. He, "PWM plus phase angle shift (PPAS) control scheme for combined multiport DC-DC converters," IEEE Trans. Power Electron., vol.27, no.3, pp.1479-1489, Mar. 2012. 